JOURNAL OF NURSING PRACTICE AND EDUCATION VOL. 02 NO. 01, DESEMBER 2021

DOI: $10.34305 /$ JNPE.V2I1.360
Ciptaan disebarluaskan di bawah Lisensi Creative Commons AtribusiNon Komersial-Berbagi Serupa4.0 .

\title{
HUBUNGAN PENGETAHUAN KESEHATAN REPRODUKSI REMAJA DAN PENGGUNAAN PANTYLINER DENGAN KEJADIAN KEPUTIHAN
}

\author{
Nanda Amalia, Nina Yusnia \\ AKBID Prima Husada Bogor \\ nandaamalia022@gmail.com
}

\begin{abstract}
Abstrak
Data penelitian menunjukkan bahwa sekitar 90\% perempuan di Indonesia mengalami keputihan. Penelitian ini bertujuan untuk mengetahui hubungan pengetahuan kesehatan reproduksi remaja mengenai penggunaan pantyliner dengan kejadian keputihan di SMK Telekomedika Bogor. Jenis penelitian menggunakan kuantitatif dan desain penelitian yang digunakan metode correlation dengan pendekatan cross sectional, populasi dan sampel berjumlah 63 siswi menggunakan total sampling. Hasil penelitian terdapat siswi yang mengetahui pengetahuan kesehatan reproduksi sebanyak 54\%, penggunaan pantyliner sebanyak 36,5\% dan mengalami keputihan 38,1\%. Hasil uji chi square didapatkan keduanya $p$ value $=0,001<0,05$ artinya ada hubungan pengetahuan kesehatan reproduksi remaja mengenai penggunaan pantyliner dengan kejadian keputihan. Diharapkan responden bisa lebih memahami tentang keputihan sehingga bisa membagi ilmunya kepada masyarakat.
\end{abstract}

Kata Kunci :Pengetahuankesehatanreproduksi, pantyliner, keputihan

Pendahuluan

Menurut World Health

Organization (WHO) Tahun 2015 jumlah remaja mencapai 1,2 miliar (Angrainy et al., 2020), menurut Survei Penduduk Antar Sensus 2015, remaja Indonesia usia 15-24 tahun berjumlah 42.062,2 juta (Rahma, 2018). Data statistic tahun 2018 bahwa penduduk di Provinsi Jawa Barat
11.358.740 (Irnawati，2016) sedangkan menurut Badan Pusat Statistik Provinsi Jawa Barat tahun 2017, jumlah remaja di Kota bogor mencapai 1.354.532 jiwa (Kuswandari, 2021).

Setiap remaja pasti mempunyai masalah kesehatan mengenai reproduksi seperti perilaku seksual pranikah, pernikahan dini, HIV/AIDS, masalah pada 
JOURNAL OF NURSING PRACTICE AND EDUCATION VOL. 02 NO. 01, DESEMBER 2021

DOI: $10.34305 /$ JNPE.V2I1.360
Ciptaan disebarluaskan di bawah Lisensi Creative Commons AtribusiNon Komersial-Berbagi Serupa4.0 . siklus menstruasi, aborsi, penyakit menular seksual, dan keputihan yang abnormal (Kartikasari et al., 2019). Keputihan memang keadaan yang wajar bagi wanita namun tetap saja akan mengganggu kenyamanan, keputihan banyak dialami pada wanita di Indonesia sebesar 90\% dikarenakan Indonesia beriklim tropis, jamur dengan mudah tumbuh dan berkembang sehingga banyak terjadi keputihan pada wanita Indonesia.

Menurut Data Survei Kesehatan Reproduksi Remaja Indonesia (SKRRI) pada tahun 2018, wanita usia 15 - 24 tahun sebagian besar mengalami keputihan, selalu terdapat kenaikan setiap tahunnya hingga $70 \%$ dan didapatkan data sebanyak $50 \%$ remaja putri mengalami keputihan (Hanipah et al., 2018), sedangkan di Kota Bogor pada tahun 2018 didapatkan banyak remaja putri yang mengeluhkan tentang keputihan, yaitu sebanyak 57\% (El-Dairi, M., \& House, 2019).

Peran pemerintah dalam menangani masalah kesehatan reproduksi remaja cukup besar, khususnya mengenai keputihan. Hal itu dapat dibuktikan dengan adanya Program Kesehatan Peduli Remaja (PKPR). Jenis kegiatan PKPR diantaranya dalam penyuluhan termasuk pemeriksaan penunjang, konseling, Pendidikan
Keterampilan Hidup Sehat (PKHS), pelatihan pendidikan sebaya dan konselor sebaya. PKPR ini bertujuan agar dapat dijangkau remaja, menyenangkan, menerima setiap remaja dengan tangan terbuka, menghargai remaja, menjaga kerahasiaan dan memperhatikan kebutuhan remaja (Rahayu, 2017).

Hasil dari studi pendahuluan yang didapatkan dari wawancara via zoom dengan 12 siswi kelas XI di SMK Telekomedika Bogor, diketahui bahwa 12 siswi pernah mengalami keputihan, 8 siswi mengatasi keputihan dengan menjaga kebersihan vagina dan 4 siswi mengatasi keputihan dengan menggunakan pantyliner. Dari hasil latar belakang tersebut, peneliti tertarik mengambil judul yaitu "Hubungan pengetahuan kesehatan reproduksi remaja dan penggunaan pantyliner dengan kejadian keputihan pada siswi Kelas XI Keperawatan di SMK Telekomedika Bogor tahun 2021"

\section{Metode}

Jenis penelitian ini menggunakan correlation dengan pendekatan cross sectional. Penelitian ini dilakukan di SMK Telekomedika Bogor pada bulan September. Populasi dalam penelitian ini adalah seluruh siswi SMK Telekomedika 
JOURNAL OF NURSING PRACTICE AND EDUCATION VOL. 02 No. 01, DESEMBER 2021

DOI: $10.34305 /$ JNPE.V2I1.360
Ciptaan disebarluaskan di bawah Lisensi Creative Commons AtribusiNon Komersial-Berbagi Serupa4.0 .
Bogor kelas XI jurusan keperawatan berjumlah 63 siswi dan dengan jumlah sampel 63 responden, dengan metode total sampling.

Pengambilan data menggunakan data primer yang didapatkan dari kuesioner dengan pertanyaan yang berhubungan dengan pengetahuan kesehatan reproduksi remaja mengenai penggunaan pantyliner dengan kejadian keputihan. Pengumpulan data menggunakan kuesioner. Analisa univariat dilakukan pada setiap variabel pengetahuan kesehatan reproduksi, penggunaan pantyliner dan kejadian keputihan. Analisa bivariat dilakukan dengan uji chi square.

\section{Hasil}

\section{Tabel 1. Distribusi Frekuensi Pengetahuan kesehatan reproduksi} di SMK Telekomedika Bogor

$$
(n=63)
$$

\begin{tabular}{lll}
\hline Pengetahuan kesehatan reproduksi & Jumlah & Persentase (\%) \\
\hline Tidak tahu & 29 & 46,0 \\
\hline Tahu & 34 & 54,0 \\
\hline Total & $\mathbf{6 3}$ & $\mathbf{1 0 0}$ \\
\hline Sumber : Data Primer Tahun 2021 & &
\end{tabular}

Tabel 1 menunjukkan pengetahuan kesehatan reproduksi di SMK Telekomedika Bogor dari 63 responden sebagian besar siswi mengetahui pengetahuan kesehatan reproduksi sebanyak 34 orang (54.0\%), sedangkan siswi yang tidak mengetahui pengetahuan kesehatan reproduksi sebanyak 29 orang $(46.0 \%)$

\section{Tabel 2. Distribusi Frekuensi Penggunaan pantyliner di SMK Telekomedika Bogor}

\begin{tabular}{lll}
\multicolumn{3}{c}{$(\mathbf{n}=\mathbf{6 3})$} \\
\hline Penggunaan pantylinner & Jumlah & Presentase (\%) \\
\hline Ya & 23 & 36,5 \\
Tidak & 40 & 63,5 \\
\hline Total & $\mathbf{6 3}$ & $\mathbf{1 0 0}$ \\
\hline \multicolumn{2}{l}{ Sumber : Data Primer Tahun 2021 }
\end{tabular}

Tabel 2 menunjukkan penggunaan pantyliner di SMK Telekomedika Bogor dibagi menjadi dua kategori Ya dan Tidak.

Dari 63 siswi didapatkan bahwa sebagian besar siswi yang tidak menggunakan pantyliner sebanyak 40 orang $(63,5 \%)$, 
JOURNAL OF NURSING PRACTICE AND EDUCATION VOL. 02 NO. 01, DESEMBER 2021

DOI: $10.34305 /$ JNPE.V2I1.360
Ciptaan disebarluaskan di bawah Lisensi Creative Commons AtribusiNon Komersial-Berbagi Serupa4.0 .

sedangkan siswi yang menggunakan pantyliner sebanyak 23 orang $(36,5 \%)$.

Tabel 3. Distribusi Frekuensi kejadian keputihan

Di SMK Telekomedika Bogor

\begin{tabular}{lcl}
\multicolumn{2}{c}{$(\mathbf{n}=\mathbf{6 3})$} \\
\hline Kejadian keputihan & Jumlah & Presentase (\%) \\
\hline Ya & 24 & 38,1 \\
Tidak & 39 & 61,9 \\
\hline Total & $\mathbf{6 3}$ & $\mathbf{1 0 0}$ \\
\hline
\end{tabular}

Sumber : Data Primer Tahun 2021

Tabel 3 menunjukkan kejadian mengalami keputihan sebanyak 39 0rang keputihan ada sisi di SMK Telekomedika (61,9\%), sedangkan yang mengalami Bogor bahwa dari 63 responden yang tidak keputihan sebanyak 24 orang (38.1\%).

Tabel 4. Hubungan Pengetahuan Kesehatan Reproduksi Remaja dengan Kejadian Keputihan di SMK Telekomedika Bogor Tahun 2021

\begin{tabular}{|c|c|c|c|c|c|c|c|c|}
\hline \multirow{3}{*}{$\begin{array}{l}\text { Pengetahuan } \\
\text { Kesehatan Reproduksi }\end{array}$} & \multicolumn{4}{|c|}{ Keputihan } & \multirow{2}{*}{\multicolumn{2}{|c|}{ Total }} & \multirow{3}{*}{ P-Value } & \multirow{3}{*}{ OR } \\
\hline & \multicolumn{2}{|c|}{ Ya } & \multicolumn{2}{|c|}{ Tidak } & & & & \\
\hline & $\mathbf{N}$ & $\%$ & $\mathbf{N}$ & $\%$ & $\mathbf{n}$ & $\%$ & & \\
\hline Tidak tahu & 18 & 28,6 & 11 & 17,5 & 29 & 46,0 & \multirow{4}{*}{0,001} & \multirow{4}{*}{7.336} \\
\hline \multirow[t]{2}{*}{ Tahu } & 6 & 9,5 & 28 & 44,4 & 34 & 54,0 & & \\
\hline & & & & & & & & \\
\hline Total & 24 & 38,1 & 39 & 61,9 & 63 & 100 & & \\
\hline
\end{tabular}

Sumber : Data Primer Tahun 2021

Analisa dari hasil penelitian pengetahuan "tahu" maka mengalami hubungan pengetahuan kesehatan keputihan sebanyak 6 orang (9,5\%). reproduksi dengan kejadian keputihan Sedangkan responden dengan pengetahuan menggambarkan bahwa sebagian besar "tidak tahu" maka tidak mengalami responden dengan pengetahuan "tidak keputihan sebanyak 11 orang $(17,5 \%)$, dan tahu" maka mengalami keputihan sebanyak responden dengan pengetahuan "tahu" 18 orang $(28,6 \%)$, responden dengan 
JOURNAL OF NURSING PRACTICE AND EDUCATION VOL. 02 NO. 01, DESEMBER 2021

DOI: $10.34305 /$ JNPE.V2I1.360
Ciptaan disebarluaskan di bawah Lisensi Creative Commons AtribusiNon Komersial-Berbagi Serupa4.0 . maka tidak mengalami keputihan sebanyak 28 orang $(44,4 \%)$.

Hasil uji chi square yang telah dilakukan mendapatkan nilai $p$ sebesar 0,001 sehingga nilai $p<0.05$. Berdasarkan uji statistik dapat disimpulkan bahwa ada hubungan antara pengetahuan kesehatan reproduksi dengan kejadian keputihan di
SMK Telekomedika. Sedangkan hasil analisis odds ratio nilainya sebesar $\mathrm{OR}=$ $7.636>1$ yang artinya bahwa siswi yang mengetahui pengetahuan kesehatan reproduksi lebih sedikit mengalami keputihan dibandingkan siswi yang tidak mengetahui pengetahuan kesehatan reproduksi.

Tabel 5. Hubungan Penggunaan Pantyliner dengan Kejadian Keputihan di SMK Telekomedika Bogor Tahun 2021

\begin{tabular}{|c|c|c|c|c|c|c|c|c|}
\hline \multirow{3}{*}{$\begin{array}{l}\text { Penggunaan } \\
\text { pantyliner }\end{array}$} & \multicolumn{4}{|c|}{ Keputihan } & \multirow{2}{*}{\multicolumn{2}{|c|}{ Total }} & \multirow{3}{*}{ P-Value } & \multirow{3}{*}{ OR } \\
\hline & \multicolumn{2}{|c|}{ Ya } & \multicolumn{2}{|c|}{ Tidak } & & & & \\
\hline & $\mathbf{n}$ & $\%$ & $\mathbf{n}$ & $\%$ & $\mathbf{N}$ & $\%$ & & \\
\hline Ya & 21 & 33,3 & 2 & 3,2 & 23 & 36,5 & & \\
\hline Tidak & 3 & 4,8 & 37 & 58,7 & 40 & 63,5 & 0,001 & 129.500 \\
\hline Total & 24 & 38,1 & 39 & 61,9 & 63 & 100 & & \\
\hline
\end{tabular}

Sumber : Data Primer Tahun 2021

Analisa dari hasil penelitian hubungan penggunaan pantyliner dengan kejadian keputihan menggambarkan bahwa sebagian besar responden yang menggunakan pantyliner maka mengalami keputihan sebanyak 21 orang $(33.3 \%)$, responden yang tidak menggunakan pantyliner maka mengalami keputihan sebanyak 3 orang (4.8\%), responden yang menggunakan pantyliner maka tidak mengalami keputihan sebanyak 2 orang $(3,2 \%)$, dan responden yang tidak menggunakan pantyliner maka tidak mengalami keputihan sebanyak 37 orang $(58,7 \%)$.

Hasil penelitian yang dilakukan uji Chi Square mendapatkan nila $p$ sebesar 0,001 sehingga $p<0,05$. Berdasarkan uji statistik dapat disimpulkan bahwa terdapat hubungan antara penggunaan pantyliner dengan kejadian keputihan di SMK Telekomedika.

Sedangkan hasil analisis odd ratio nilainya sebesar $129.500>1$ yang artinya 
JOURNAL OF NURSING PRACTICE AND EDUCATION VOL. 02 No. 01, DESEMBER 2021

DOI: $10.34305 /$ JNPE.V2I1.360
Ciptaan disebarluaskan di bawah Lisensi Creative Commons AtribusiNon Komersial-Berbagi Serupa4.0 bahwa siswi yang tidak menggunakan pantyliner lebih sedikit mengalami keputihan dibandingkan dengan siswi yang menggunakan pantyliner.

\section{Pembahasan}

Hasil penelitian dari 63 responden sebagian besar siswi mengetahui pengetahuan kesehatan reproduksi sebanyak 34 orang (54.0\%). Pengetahuan kesehatan reproduksi dapat diperoleh dari berbagai tempat salah satunya sekolah, media massa, orang tua bahkan teman.

Seperti yang dikatakan oleh Leiliana (2010) bahwa semakin baik pengetahuan mengenai kesehatan reproduksi maka akan semakin memahami bagaimana cara menjaga kesehatan reproduksi juga, karena kesehatan reproduksi sangat penting dijaga untuk mempertahankan fertilitas. Dari penelitian tersebut didapatkan bahwa siswi sebagian besar sudah mengetahui pengetahuan tentang kesehatan reproduksi (Leiliana, 2010).

Penelitian ini pun sama dengan penelitian oleh Dewi bahwa tingkat pengetahuan remaja mengenai kesehatan reproduksi sangat baik (Irianti, D., \& Tiarahma, 2021). Hasil penelitian dari 63 responden didapatkan bahwa sebagian besar responden tidak menggunakan pantyliner sebanyak 40 orang $(63.5 \%)$.

Beberapa orang percaya bahwa menggunakan pantyliner diperlukan untuk mengatasi keputihan, namun akan lebih baik jika pantyliner digunakandengan tetap menjaga agar daerah kemaluan tetap kering, menggunakan pantyliner yang tidak baik akan memungkinkan terjadinya keputihan akibat peningkatan suhu, dan kelembaban, serta memudahkan perkembangbiakan bakteri. Dari penelitian di atas responden yang tidak menggunakan pantyliner lebih banyak dibanding dengan responden yang menggunakan pantyliner.

Penelitian yang sama dilakukan oleh Anisa bahwa sebagian besar remaja tidak menggunakan pantyliner di SMA Kota Padang berdasarkan hasil wawancara (Persia et al., 2016).

Hasil penelitian dari 63 responden yang tidak mengalami keputihan sebanyak 39 orang $(61,9 \%)$. Keputihan adalah salah satu keluhan yang paling umum di kalangan wanita, dan terkadang masih dianggap sebagai hal yang sepele. Maka dari itu sebagai wanita sangat penting untuk menjaga kebersihan genitalia, usahakan agar daerah kemaluan tetap kering dan tetap bersih. Dari hasil penelitian di atas menunjukkan bahwa sebagian besar siswi 
JOURNAL OF NURSING PRACTICE AND EDUCATION VOL. 02 No. 01, DESEMBER 2021

DOI: $10.34305 /$ JNPE.V2I1.360
Ciptaan disebarluaskan di bawah Lisensi Creative Commons AtribusiNon Komersial-Berbagi Serupa4.0 . tidak mengalami keputihan berarti siswi tersebut mampu menjaga kebersihan alat genitalianya.

Penelitian yang sama juga dilakukan oleh Antika dengan judul hubungan pengetahuan tentang personal hygiene terhadap kejadian keputihan pada siswi kelas X di MAN 1 Surakarta (Mayssara A. Abo Hassanin Supervised, 2017).

Dari hasil penelitian menunjukkan terdapat hubungan antara pengetahuan kesehatan reproduksi dengan kejadian keputihan. Peneliti lainnya juga menyampaikan hal yang sama, yang dilakukan Nurlaila yang meneliti hubungan pengetahuan personal hygiene dengan kejadian keputihan pada remaja putri dan terdapat bahwa ada hubungan antara pengetahuan dengan kejadian keputihan (Nurlaila, \& Zakir, 2016).

Dari hasil penelitian menunjukkan terdaat hubungan antara penggunaan panylimer dengan kejadian keputihan.

Hal ini pun sejalan dengan penelitian yang dilakukan oleh Diva Nurhasanah (2019) bahwa terdapat hubungan perilaku penggunaan pantyliner dengan kejadian keputihan pada remaja putri di Pondok Pesantren Al-Masyhuriyah Bukit Raya Kecamatan Tenggarong
Seberang (Nurhasanah, D., \& Wijayanti, 2019).

\section{Kesimpulan}

Sebagian besar siswi mengetahui kesehatan reproduksi sebanyak 34 orang (54\%), sebagian besar siswi tidak menggunakan pantyliner sebanyak 40 orang (63.5\%), sebagian besar siswi tidak mengalami keputihan sebanyak 39 orang $(61,9 \%)$, terdapat hubungan pengetahuan kesehatan reproduksi dengan kejadian keputihan, terdapat hubungan penggunaan pantyliner dengan kejadian keputihan, dan terdapat hubungan pengetahuan kesehatan reproduksi remaja dan penggunaan pantyliner dengan kejadian keputihan.

\section{Saran}

Dari penelitian ini diharapkan dapat digunakan untuk bahan pembelajaran, dan lebih memahami tentang keputihan sehingga bisa membagi ilmunya kepada masyarakat dalam upaya preventif berupa perawatan kesehatan diri sendiri dan masyarakat

\section{Daftar Pustaka}

El-Dairi, M., \& House, R. J. (2019). Optic Nerve Hypoplasia. In Handbook Of Pediatric Retinal OCT And The EyeBrain Connection. 285-287. https://doi.org/https://doi.org/10.1016/ B978-0-323-60984-5.00062-7

Hanipah, N., Nirmalasari, N., \& Hormone, 
JOURNAL OF NURSING PRACTICE AND EDUCATION VOL. 02 NO. 01, DESEMBER 2021

DOI: $10.34305 /$ JNPE.V2I1.360
Ciptaan disebarluaskan di bawah Lisensi Creative Commons AtribusiNon Komersial-Berbagi Serupa4.0 .
L. (2018). Gambaran Pengetahuan Dan Sikap Vulva Hygiene Dalam Menangani Keputihan (Fluor Albus) Pada Remaja Putri. 132-136.

Irianti, D., \& Tiarahma, L. (2021). Program Studi Diploma Tiga Keperawatan Stikes Intan Martapura, Indonesia Tabel Berdasarkan tabel 1, mayoritas responden berada pada rentang usia 13-14 tahun sebanyak 38 orang ( 63 , $3 \%$, dan usia menarche terbanyak pada. 20-23.

Irnawati. (2016). Faktor Yang Berhubungan Dengan Pengetahuan Remaja Putri Kelas IV,V,VI Tentang Menarche Di SD Negeri Karangkidul II Kecamatan Benjeng Kabupaten Gresik.

http://repository.unair.ac.id/54385/13/

FK. BID. 57-16 Irn f-min.pdf

Kartikasari, D., Ariwinanti, D., \& Hapsari, A. (2019). Gambaran Pengetahuan Kesehatan Reproduksi Siswa Smk Wisnuwardhana Kota Malang. Preventia: The Indonesian Journal of Public Health, 4(1), 36. https://doi.org/https://doi.org/10.17977 /um044v4i1p36-41

Kuswandari, D. A. (2021). Master File Desa Provinsi Jawa Barat 2021 (2 ed.). Badan Pusat Statistik Provinsi Jawa Barat. file:///C:/Users/USER/Documents/KTI NANDA/data remaja kota bogor.pdf

Leiliana. (2010). Kuesioner penelitian Hubungan Pengetahuan Remaja Putri Terhadap Kesiapan Menghadapi Menarche.

https://id.scribd.com/doc/125047244/

Kuisioner-Menarche
Mayssara A. Abo Hassanin Supervised, A. (2017). Hubungan Pengetahuan Tentang Personal Hygiene Terhadap Kejadian Keputihan Pada Siswi Kelas $\mathrm{X}$ di MAN 1 Surakarta. Paper Knowledge . Toward a Media History of Documents.

Nurhasanah, D., \& Wijayanti, T. (2019). Hubungan Perilaku Penggunaan Pantyliner dengan Kejadian Flour Albus pada Remaja Putri di Pondok Pesantren Al-Masyhuriyah Bukit Raya Kecamatan Tenggarong Seberang. Journal Borneo Student Research, 5. https://journals.umkt.ac.id/index.php/b sr/article/download/1070/329

Nurlaila, \& Zakir, M. (2016). Hubungan Pengetahuan dan Personal Hygiene dengan Kejadian Keputihan. Jurnal Keperawatan, 11(1), 4-7.

Persia, A., Gustia, R., \& Bahar, E. (2016). Hubungan Pemakaian Panty Liner Dengan Kejadian Fluor Albus Pada Siswi SMA Di Kota Padang Berdasarkan Wawancara Terpimpin (Kuesioner). Jurnal Kesehatan Andalas, 4(2), 509-512. https://doi.org/https://doi.org/10.25077 /jka.v4i2.284

Rahayu, E. P. (2017). Gambaran Pengetahuan Remaja Putri Tentang Keputihan Di Pondok Pesantren Kuno Putri Mbalong Nogotirto Gamping. http://repository.unjaya.ac.id/2427/2/E ndah Puji Rahayu \%281114111\%29nonfull.Pdf

Rahma, M. (2018). Hubungan Antara Pengetahuan Seksualitas Dengan Perilaku Seksual Remaja Di Sma Negeri 1 Subang. Jurnal Bidan, 5(1), 17-25. 
JOURNAL OF NURSING PRACTICE AND EDUCATION VOL. 02 No. 01, DESEMBER 2021

DOI:10.34305/JNPE.V2I1.360
Ciptaan disebarluaskan di bawah Lisensi Creative Commons AtribusiNon Komersial-Berbagi Serupa4.0 . (c) (i) (2)(2) 